\title{
Cláusulas causais adendos: Uma variante de ordenação?
}

\author{
Maria da Conçeição de Paiva \\ Universidade Federal do Rio de Janeiro
}

\section{Abstract}

In this article I discuss two forms of posposed causal clauses in oral discourse: $Y$ porque $X$ (" $Y$ because $X$ ") and $Y$ pausa porque $X$ (" $Y$ pause because $X ")$. By means of quantitative analysis, I demonstrate that these forms cannot be considered structural alternatives for expressing causal relation in all environments. Although either one may occur in some contexts, afterthought clauses share different features and play a specific role in the process of verbal interaction. 


\section{INTRODUG̣̃̃O}

To português falado há duas possibilidades de posposição de cláusulas causais: as formas y porque $X$ ou y pausa porque $X$.

A primeira esquematiza sequêencias causais em que a cláusula causal compõe com a cláusula efeito que a antecede uma única unidade entonacional, como no exemplo (1):

(1) A maioria da classe média sem dúvida alguma come em casa porque os restaurantes são proibitivos.

A segunda forma, ilustrada por (2), se refere a enunciados em que as cláusulas causais são desligadas da cláusula efeito por uma pausa, constituindo uma unidade entonacional independente, como ilustrado por (2):

(2) Você. vê: nós começamos aqui, né? Tá só esqueleto. Ainda- Estamos aqui ainda. Porque o dinheiro num dá pra construir ali. Comprei o estofado, comprei uma porção de coisas...

A cláusula introduzida por porque em (2) é denominada por Chafe (1984) de "afterthought". Seguindo uma tradução proposta por Marcuschi (1989), prefiro chamá-la adendo.

Este artigo se propõe a discutir alguns aspectos sobre a relação paradigmática entre essas duas formas, partindo de uma análise quantitativa que considera aspectos lexicais, discursivos e interacionais envolvidos no seu uso no discurso oral. A relação entre esses níveis de análise apontará a dificuldade de interpretação dos resultados e da própria relação entre as formas pressupostamente "alternantes". 


\section{DISTRIBUICAO E NATUREZA DOS ADENDOS}

De um ponto de vista estritamente estatístico, a posposição das cláusulas causais sob a forma de $\boldsymbol{Y}$ porque $\boldsymbol{X}$ é muito mais freqüente, nas amostras examinadas, ${ }^{1}$ do que a forma $y$ pausa porque $X$. De um total de 2352 dados analisados, mais da metade (71\%) são de enunciados causais em que a cláusula causal e a cláusula efeito integram uma única unidade entonacional.

preciso acentuar que, em princípio, os mesmos conectores (que e porque) podem ser usados para explicitar a relação de causalidade nas duas formas de posposição. Nos enunciados $Y$ pausa porque $X$, o conector pode ser visto como o elemento formal que garante a relação semântica que pode ser comprometida pela dissociação prosódica entre os dois segmentos do enunciado. De uma certa forma, a presença do conector é inerente à própria definição de adendo.

A tabela 1 apresenta a distribuição dos adendos encontrados nas amostras, de acordo com o conector que os introduz, considerando, inclusive, o caso de adendos sem conector. A baixa percentagem de adendos desse último tipo corrobora o que se disse acima acerca da indissociabilidade entre conector e adendo. A presença de uma marca formal na introdução desse tipo de cláusula é quase categórica.

A distribuição dos adendos de acordo com os conectores que e porque mostra que, mesmo se o conector porque é a marca formal preferencialmente utilizada nesse tipo de posposição $(56.92 \%)$, não é desprezível a percentagem de cláusulas adendos introduzidas por que $(41.36 \%)$.

As explicações correntes de adendo acentuam, sobretudo, seu papel na organização textual e no processo de interação verbal. Mais precisamente, o adendo é concebido como um processo de autoedição ("self-editing"), principalmente nos discursos monológicos, ou como uma estratégia conversacional (Chafe, 1984; Ford, 1988) .

$\mathrm{Na}$ primeira perspectiva, as cláusulas adendo decorrem do próprio processamento do discurso oral, ou seja, da avaliação do falante quanto à necessidade de acréscimo de informação em um ponto do discurso onde está impossibilitado de alterar características prosódicas do discurso anterior. $\mathrm{Na}$ segunda perspectiva, 
os adendos, por se situarem em pontos onde podem ocorrer mudanças de turno, possuem papel nitidamente interacional, pois constituem recursos associados à recepção e compreensão de mensagens.

A análise da posposição das cláusulas causais no português oral faz aparecerem, no entanto, restrições impostas pelo próprio conector utilizado na introdução do adendo. Em muitos enunciados causais da forma $Y$ pausa porque $X$, a dissociação prosódica entre os segmentos causa e efeito, parâmetro definidor do adendo, está ligada ao próprio elemento relacional utilizado.

\section{RESTRICOES LEXICAIS}

De acordo com a tabela $1,41.36 \%$ das cláusulas adendo são introduzidas pelo conector que, elemento multifuncional no português moderno. Além de poder ser utilizado para explicitar a relação causa-conseqüência, é elemento de conexão de outras relações semânticas interproposicionais. Atua igualmente na configuração de diversas relações sintáticas: liga-se a constituintes de uma cláusula matriz (seja na introdução de complementos verbais ou de cláusulas relativas) ou à cláusula como um todo. $\overline{\mathbf{E}}$, portanto, um elemento relacional ambíguo. A co-ocorrência de traços prosódicos pode ser um fator decisivo na determinação do escopo de uma cláusula introduzida por que e do nexo semântico por ele explicitado.

Muitos dos enunciados $y$ pausa porque $X$ com o conector que seriam ambíguos não fosse a conjugação de traços prosódicos particulares. Os exemplos (3) e (4), abaixo, são ilustrações dessa possibilidade.

(3) F- Acho um cachorro bacana, assim, é diversido, que ele éque ele já foi roubado, ele já foi- ele já foi preso- ele já foi mu- Engraçado que ele leva uma- um- um negócio que ele leva nas costas. Aquele negócio de botar no cavalo, pra montar. Ele- ele leva. Um dia ele levou um tombo com aquilo. Que estava pesado. Eu ri à beça. (C., M. So., 51, 111)

(4) Meu filho gosta de... de pescar, gosta de fazer, fazer churrasco. Quando ele era solteiro, eu estava sempre com festa aqui na minha casa. Que ele fazia churrasco, fazia festinha de- junina, sabe? Gosta de fazer e fazia. Enfeitava tudo aqui, o quintal. (C., Nad., 36, 159) 
Os enunciados (3) e (4) caracterizam um contexto onde seria possível interpretar a cláusula introduzida por que como uma oração relativa modificadora de um sintagma nominal de uma oração matriz (ele levou um tombo com aquilo que (= o qual) estava pesado e eu estava sempre com festa aqui na minha casa que (= onde) ele fazia churrasco, fazia festinha de- junina, sabe?) Nos dois casos, a proposição introduzida por que é sintática e semanticamente ambígua.

A ligação entonacional entre os dois segmentos dos enunciados (3) e (4) criaria uma configuração sintagmática favorável à interpretação acima, determinando tanto o escopo da cláusula introduzida por que como a sua função semântica. Que seria interpretável mais facilmente como uma retomada anafórica de um nome diretor.

A independência entonacional entre o segmento introduzido por que e o segmento precedente, se não anula completamente a ambigüidade, favorece fortemente uma interpretação de relação causal entre os dois segmentos constituintes do enunciado, determinando um escopo distinto: que está ligado a todo o segmento anterior e não a um constituinte deste. Essa relação seria parafraseável por porque.

3a- Ele levou um tombo com aquilo porque estava pesado.

4a- Eu estava sempre com festa aqui na minha casa porque ele fazia churrasco, fazia festinha de- junina, sabe?

O exemplo (5) coloca problemas de natureza semelhante.

(5) F- Minha filha é muito linda, mas eu num sinto falta dela não, porque ela- ela lá vive muito bem, sabe? Eu acho que ela queria- não queria ter nada e viver junto comigo. Que ela sente muita falta de mim. Porque como eu disse pra você, né? (C., Joa., 10, 67-68)

No enunciado (5), a cláusula que ela sente muita falta de mim poderia ser interpretada como um segundo argumento do verbo achar, uma segunda opinião acrescentada "a posteriori" (Eu acho que ela sente muita falta de mim). Essa interpretação seria favorecida pela ligação prosódica que acarretaria maior contiguiidade entre os dois segmentos. 
Da mesma forma que nos exemplos (3) e (4), na medida em que a cláusula introduzida por que constitui uma unidade prosódica independente favorece a interpretação de relação causal entre os dois segmentos:

Eu acho que ela queria- não queria ter nada e viver junto comigo porque ela sente muita falta de mim.

As observações feitas até aqui aplicam-se exclusivamente ao conector que, uma vez que o conector porque, pelo menos nos aspectos em análise, não se caracteriza pela mesma ambiguiidade. Porque é usado basicamente como conector de causalidade.

Tomando-se apenas os dados de sequiências causais construídas com que, pode-se verificar facilmente a forte correlação entre ambiguidade do enunciado e a forma $Y$ pausa porque $X$. Como bem o mostram as estatísticas da tabela 2, a probabilidade de estruturação sintática da relação de causalidade na forma de $y$ pausa porque $X$ é muito acentuada quando o nexo de causalidade entre os dois segmentos pode ser comprometido pela superposição de outros significados. O que parece bastante coerente com uma tendência mais geral de evitar superposição de interpretações de um mesmo enunciado, de tornar o conteúdo semântico o mais transparente possível.

Os resultados da tabela 2 refletem a associação entre a forma $y$ pausa porque $X$ e a multifuncionalidade de um elemento lingüístico ( $q u e$ ), evidenciando a interdependência entre propriedades lexicais e os processos de estruturação sintática presentes no discurso oral. Intendependência que, não ocorrendo nos adendos introduzidos por porque, está na origem de uma assimetria entre os dois tipos de cláusulas pospostas.

Essa assimetria entre que e porque tem conseqüências inevitáveis no plano de definição do "spectrum" da variação e está na origem de uma relação muito mais complexa entre as duas formas de posposição de cláusulas causais. Se existe efetivamente uma relação paradigmática entre $Y$ porque $X$ e $Y$ pausa porque $X$, ela é dependente de aspectos lexicais, pois requer levar em consideração o elemento que estabelece a conexão. A alternância entre $\boldsymbol{Y}$ porque $\dot{X}$ e $\boldsymbol{Y}$ pausa porque $\boldsymbol{X}$ fica restrita àqueles contextos em que a dissociação prosódica não é praticamente obrigatória como meio de assegurar a relação semântica de causalidade. 
A complexa relação entre características dos próprios elementos conectores e dissociação prosódica vai revelar a existência de lacunas e superposições no "spectrum" variável. Nos enunciados construídos com porque, a variação é sempre possível, o que equivale a dizer que $\boldsymbol{Y}$ porque $X$ pode alternar com $Y$ pausa porque $X$. Assim, em um enunciado como (1) (A maioria da classe média sem dúvida alguma come em casa porque os restaurantes são proibitivos), poder-se-ia ter a dissociação prosódica entre os dois segmentos (A maioria da classe média sem dúvida alguma come em casa. Porque os restaurantes são proibitivos), uma vez que nenhuma restrição derivada do próprio elemento conector controlaria a possibilidade de alternância. No entanto, nos enunciados construídos com que a alternância entre $y$ porque $X$ e $Y$ pausa porque $X$ fica controlada pelo próprio elemento conector. Mais precisamente, a relação semântica só poderia ser realizada, pelo menos de forma mais transparente, pela forma $Y$ pausa porque $X$, uma vez que a dissociação prosódica e sintática é necessária para evitar possíveis ambiguiidades do enunciado. Assim, nos exemplos (3) e (4) discutidos acima, a única forma possível é $y$ pausa porque $X$. A alternância nos enunciados construídos com que é muito mais restrita do que a alternância nos enunciados com porque, o que resulta no seguinte quadro:

$\begin{array}{cll}\boldsymbol{Y} \text { porque } \boldsymbol{X} & \boldsymbol{Y} \text { pausa porque } \boldsymbol{X} \\ \mathrm{O} & ? & \text { que } \\ \text { porque } & \text { porque }\end{array}$

Havendo uma lacuna no esquema, provocada ela própria por restrições ligadas ao elemento conector que, a relação paradigmática entre as formas $Y$ porque $X$ e $Y$ pausa porque $X$ se restringe forçosamente aos enunciados construídos com o conector porque.

Dado o quadro acima, poder-se-ia levantar a hipótese de que a variação de fato ocorra no nível lexical e a pergunta a ser feita seja relativa às possibilidades de alternância entre os conectores que e porque. 


\section{ALGUNS ASPECTOS DISCURSIVOS}

A análise de alguns aspectos discursivos ligados às formas $\boldsymbol{Y}$ porque $\boldsymbol{X}$ e $\boldsymbol{Y}$ pausa porque $\boldsymbol{X}$ vai nos ajudar a demonstrar que a questão é mais complexa e implica a conjugação de três níveis diferentes: sintático, lexical e discursivo.

Pode-se esperar que a posposição das cláusulas causais seja controlada por princípios mais gerais ligados à organização do discurso. Princípios como os que determinam, por exemplo, a relação entre distribuição de informação e unidades entonacionais. Para verificar essa hipótese, faz-se necessário verificar a correlação entre a categoria informacional das cláusulas causais e as formas de posposição em análise.

Simplificando a questão, reduzirei as categorias informacionais às categorias novo/velho e as definirei de maneira bastante estrita Informação nova é compreendida como informação não mencionada no discurso anterior ao enunciado causal e não inferível a partir deste. Informação velha já foi mencionada no discurso, reenvia ao discurso anterior, constituindo quase uma repetição.

Os dois segmentos do enunciado causal, a cláusula causal e a cláusula efeito, são analisados pelo prisma da sua categoria informacional. Ressalta dos resultados expostos na tabela 3 a predominância de cláusulas causais que introduzem informação nova, ou seja, não mencionada no discurso anterior. Tal correlação é independente das características entonacionais da cláusula causal posposta: tanto as que se ligam quanto as que se separam do segmento precedente são pontos de acréscimo de informação (59.78\% e 72.68\%). Desta forma, a categoria informacional da cláusula causal em nada avança a nossa compreensão das restrições sobre a forma $Y$ pausa porque $X$.

Admitindo que informação nova é, geralmente, introduzida na segunda posição, a correlação acima encontra uma explicação natural.2

Para dar conta das possibilidades de alternância entre $\boldsymbol{Y}$ porque $X$ e $Y$ pausa porque $X$, é preciso considerar a categoria informacional da cláusula efeito ligada a uma cláusula causal com informação nova. Somente essa análise faz aparecer a configuração discursiva distinta de cada uma das formas de posposição, como se pode constatar pelos resultados expostos na tabela 4 . 
Os enunciados constituídos por dois segmentos da mesma categoria tendem a se apresentar sob a forma de $Y$ pausa porque $X$. Ao contrário, a conexão de um segmento que retoma $o$ discurso anterior fazendo-o progredir pelo acréscimo de informações novas se realiza, mais frequientemente, sob a forma $Y$ porque $X$. Essa assimetria na distribuição de informação nos enunciados $Y$ porque $X$ e $Y$ pausa porque $X$ é esquematizada abaixo:

$\begin{array}{rrrr}Y \text { porque } X & & Y \text { pausa } & \text { porque } X \\ \text { velho } & \text { novo } & \text { novo } & \text { novo }\end{array}$

Um principio mais geral de organização do discurso prevê a correspondência entre unidade de informação e unidade entonacional: em cada unidade entonacional só pode ser codificada uma unidade de informação nova. Se a forma $Y$ pausa porque $X$ conecta duas unidades de informação nova, elas devem ser separadas prosodicamente, a fim de obedecer a um princípio mais geral de organização do discurso.

Ainda segundo o mesmo princípio, a progressão de informação tomando por ponto de partida uma informação já apresentada no discurso se realiza, em geral, no interior de uma única unidade entonacional.

A configuração informacional particular dos enunciados $Y$ pausa porque $X$ está, portanto, diretamente, associada à realização de cada uma das cláusulas como uma unidade entonacional independente.

\section{ESPECIFICIDADES INTERACIONAIS DOS ADENDOS}

As diferenças entre $Y$ porque $X$ e $Y$ pausa porque $X$ ficam mais evidentes ainda à luz do papel interacional desempenhado pelas cláusulas adendo. Do ponto de vista interacional, os adendos se situam em pontos onde o interlocutor pode interferir para tomar o turno de fala, para discordar, concordar ou apenas estimular a continuação do discurso. A análise das cláusulas adendo inseridas em longos turnos de fala mostra que elas ocorrem em contextos onde é virtual uma pergunta por quê solicitando o acréscimo de informação. Ao acrescentar a cláusula adendo, o falante antecipa-se à possível interferência do interlocutor, apresentando a elaboração causal que lhe poderia ser solicitada. Esta função antecipatória 
das cláusulas causais adendos pode se apresentar sob diversas formas. O trecho (6) ilustra uma realização possível dessa função.

Em (6), o discurso gira em torno do tópico viagens e passeios que o falante faz habitualmente com a família, quando o entrevistador interfere.

(6) E- E você gosta de viajar?

F- Gosto. Estou quase sempre viajando, porque nós tínhamos um sítio, sabe? aí. Uma fazenda, mas eu num gostava de ir pra lá não. Aí- Porque num tinha quase ninguém. $\mathrm{E}$ uma fazenda. ("A gente") num tinha vizinho, num tinha nada, mas tinha esses negócio assim- tinha- tinha piscina, tinha quadra de vôlei que nós mandamos fazer, mas- (C., Ad. M., 61, 153)

No trecho transcrito acima, a falante inicia seu discurso com a afirmação de que gosta de viajar e que o faz sempre. Este início autorizaria a conclusão de que a falante gosta igualmente de viajar para a fazenda que a família possuía. A ocorrência de mas bloqueia esta conclusão, invertendo a orientação argumentativa do discurso: (a falante não gostava de viajar para a fazenda). Após a cláusula introduzida pelo mas, o falante faz uma pausa, seguida de uma hesitação (aí), que poderia ser preenchida pelo interlocutor (no caso, o entrevistador) para questionar acerca da mudança de orientação argumentativa no enunciado anterior. A cláusula adendo porque num tinha quase ninguém explica a razão da inversão argumentativa, antecipando, assim, uma resposta à pergunta que poderia ser colocada.

Uma cláusula causal adendo pode também estar ligada a uma cláusula efeito que retifica uma afirmação anterior do interlocutor, como em (7).

(7) E- E qual era a faixa de idade daqueles seus amigos do bairro?

F- A faixa? Eu acho que era a mais nova. Acho que era de catorze até- Tinha gente de vinte um anos, tem dezenove, dezoito. Tinha de tudo, até meu pai era. Tinha de todas as faixas de idade.

E- E quem é o seu melhor amigo, ou a sua melhor amiga?

F- Ficou difícil. Deixa eu ver. Daqui ou da escola? 
E- O seu melhor amigo, a sua melhor amiga, no geral?

F- Colega, né? Porque amigo mesmo a gente num tem, né? Deixa eu ver. Colega mesmo que eu ando mais é a Kátia, que eu ando mais, e de garoto, que eu ando mais assim, vivo conversando, assim, é o Alexandre, o garoto que mora aqui também. (C., Ad. M., 61, 31-32)

No exemplo (7), a falante é solicitada a dizer o nome da sua melhor amiga, termo do qual ela discorda. Na sua perspectiva, não se pode falar em amigo e ela prefere colega (colega, né?). Instaura-se uma discordância entre $o$ entrevistador e a falante. $O$ ato de discordar implica uma justificativa, sob pena de que esta seja solicitada. A falante justifica a sua preferência pelo termo colega através do acréscimo da cláusula adendo (porque amigo mesmo a gente num tem, né?) . A cláusula introduzida por porque está relacionada ao próprio ato de discordância, isto é, o justifica. A cláusula causal adendo em (7) possui a forma de uma afirmação genérica, impessoal, o que, sob certos aspectos, atenua as consequiências negativas do próprio ato de discordância. Justificando-se através de uma afirmação genérica, a falante garante a melhor aceitação da discordância .

Em alguns enunciados, a função antecipatória da cláusula adendo é explicitada pelo próprio falante que a faz preceder de uma pergunta por quê, como ocorre no exemplo (8) .

(8) F- A Roberta é amiga da Bruna e o Roberto é amigo meu. E- Ah é? Que legal! Eles moram por aqui por perto também? F- Não. Moram na outra rua.

$\mathbf{E}-\mathbf{E}$ aqui nessa rua, você brinca muito com os amiguinhos? F- Tem alguns que não deixam brincar.

E- Por quê?

F- Porque eles falam- "Depois de acabar o jogo". Depois acomeçou- depois eu falo pra eles se eu posso jogar, depois eles falam não.

E- Mas por quê? Eles são maiores que você e você é pequenininho. $\mathrm{E}$ por isso?

F- $\mathbf{E}$. Tem o Alfredo que é muito chato. Sabe por quê? Que ele- que ele num deixa eu brincar.

E- Por quê? (C., Nel., 49, 40-41) 
No exemplo (8), o falante emite sua opinião acerca do vizinho. Segundo ele o Alfredo é muito chato. Avaliando que o interlocutor pode solicitar uma justificativa da opinião emitida, o falante acrescenta a cláusula adendo que justifica a sua caracterização do vizinho (que ele num deixa eu brincar). A introdução da cláusula adendo é precedida pela pergunta por quê, colocada pelo próprio falante, que torna explícita a sua avaliação de que o discurso anterior requer elaboração adicional.

Em (8), a pergunta por quê concretiza a antecipação do falante à intervenção do interlocutor. Embora endereçada ao ouvinte, a pergunta é retórica, pois só pode ser respondida pelo falante.

Nos exemplos analisados, ainda que ligeiramente distintos entre si, a cláusula causal sob a forma de adendo é resultado da avaliação que o falante faz do seu próprio discurso. Pelo acréscimo da cláusula adendo, o falante como que reconhece que há pontos do seu discurso onde o ouvinte poderia tomar o turno, interferir, discutir opiniões apresentadas, solicitar informação adicional. Ao apresentar a cláusula adendo, o falante se antecipa e bloqueia a interferência do interlocutor.

A função interacional das cláusulas adendo fica ainda mais evidente, quando consideramos sua ocorrência em amostras de conversação espontânea.

(9) $F_{1}$ - Uma carta da Alemanha levou oito dias pra chegar ao Brasil.

$\mathrm{F}_{2^{-}}$Estou admirado.

$\mathrm{F}_{1}-\mathrm{Oi}$ ?

$\mathrm{F}_{2^{-}}$Porque ela vem de avião. Será que eles mandaram de navio? (Inf., sit. 12)

No exemplo (9), $F_{2}$ expressa sua surpresa pela demora de uma carta da Alemanha para o Brasil. $F_{1}$, por sua vez, manifesta sua incompreensão diante da surpresa de $\mathrm{F}_{2}$, incompreensão explicitada na interrogação (oi?) que poderia perfeitamente ser substituída por uma pergunta por quê. Através da sua interrogação, $F_{1}$ solicita a $\mathrm{F}_{2}$ que explicite a razão da sua surpresa. Solicitação atendida na segunda intervenção de $\mathrm{F}_{2}$ pelo acréscimo da cláusula causal adendo introduzida por porque (porque ela vem de avião). 
O exemplo (9) ilustra igualmente o acréscimo de um adendo a partir da intervenção do interlocutor. ${ }^{3}$

A tabela 5 apresenta os resultados relativos à distribuição das cláusulas adendo de acordo com diversas funções por elas desempenhadas no discurso oral.

As cláusulas adendos, vistas pelo ângulo da sua função interacional, visam à própria continuação do discurso. Ao acrescentar uma informação que julga que lhe pode ser solicitada, o falante atua de forma a dar continuidade ao seu próprio discurso. O que evidencia a funcionalidade das cláusulas adendo na organização da interação verbal.

\section{CONOLUSAO}

Do que se desenvolveu até esse ponto, salientaram-se peculiaridades da forma $Y$ pausa porque $X$ que conduzem à reflexão acerca da equivalência entre as formas de posposição de cláusulas causais. Parece-nos que as diferenças superam em muito as semelhanças, tornando difícil falar de relação paradigmática entre duas formas variantes de posposição da cláusula causal.

A análise permite falar em duas formas distintas de posposição da cláusula causal, uma vez que cláusulas causais pospostas que seguem entonação continuativa da cláusula efeito e cláusulas pospostas que possuem um encontro entonacional próprio se distinguem sob diversos aspectos.

As cláusulas causais adendo partilham, sem dúvida, algumas das características das cláusulas pospostas que seguem entonação continuativa. Do ponto de vista semântico, ambas realizam um ato de fala diferente do realizado pelo segmento que as antecede, ou seja, o ato de justificar uma enunciação. Ambas são formas de expressão da causalidade, apenas no sentido mais amplo desse termo, incluindo aí a relação de justificação. Por esse prisma, podem, portanto, ser consideradas equivalentes, possibilidades disponiveis no interior de um mesmo paradigma.

Aparentemente seriam intersubstituíveis também no plano discursivo, isto é, seriam alternativas discursivamente equivalentes para a expressão da relação de causalidade, uma vez que, do ponto 
de vista da sua função na organização do discurso, outra similaridade aparece: os dois tipos de cláusulas causais pospostas constituem pontos de introdução de informação nova no discurso. Essa aparente equivalência se desfaz, entretanto, quando se considera o enunciado causal como um todo. As duas formas de posposição se inserem em configurações informacionais totalmente distintas, embora ambas possam ser atribuídas à ação do mesmo princípio que rege a relação entre distribuição de informação e unidades entonacionais.

Do ponto de vista interacional, as cláusulas causais adendo se peculiarizam em relação às cláusulas pospostas ligadas por desempenharem funções que não estão claramente associadas a estas últimas. As cláusulas causais adendo, como vimos, ocorrem, predominantemente, em situações discursivas em que seria possível a colocação de uma pergunta por quê pelo interlocutor. Possuem um papel na própria organização da interação verbal, constituem uma estratégia pela qual o falante fornece antecipadamente a informação que lhe poderia ser solicitada. A dissociação entonacional entre os dois segmentos do enunciado $Y$ pausa porque $X$ é o próprio índice da função interacional deste tipo de realização da relação causal.

As diferenças constatadas não chegariam a impedir que se fale de formas alternantes de posposição, embora tal afirmação implique uma definição de equivalência. Restringindo-se à equivalência semântica, pré-requisito satisfeito pelas formas em questão, pode-se dizer que se trata de formas alternantes discursiva e interacionalmente condicionadas. Assim, a categoria informacional da cláusula efeito pode ser tomada como um fator condicionador da forma $Y$ pausa porque $X$. Quando a cláusula efeito codifica informação nova e se liga a uma cláusula causal que, via de regra, codifica informação nova, favorece a ocorrência da dissociação prosódica. Ou, ainda, posso tomar como fator de favorecimento de uma ou outra forma de posposição a avaliação que o falante faz do seu discurso no transcorrer deste.

o problema é que essa explicação é insatisfatória face à correlação entre cláusulas introduzidas por que e a forma $\boldsymbol{Y}$ pausa porque $X$. Como se constatou no item 3, essa correlação faz com que, em uma grande parte dos enunciados construídos com que, a substituição de uma forma pela outra seja fortemente restrita. 
que necessariamente restringiria a explicação acima às possibilidades de cláusulas porque ligadas e não ligadas prosodicamente ao segmento anterior.

Essa interrelação entre os níveis lexical, semântico e discursivo nos leva a questionar a própria natureza da forma $\boldsymbol{Y}$ pausa porque $X$. A forma $\boldsymbol{Y}$ porque $\boldsymbol{X}$ pode ser caracterizada como uma estrutura pela qual se subordinam dois atos de fala distintos. Podemos nos perguntar se a forma $Y$ pausa porque $X$ pode ser considerada igualmente subordinativa. Os conectores que e porque que introduzem as cláusulas causais adendos podem ser incluídos no rol dos conectores subordinativos ou trata-se de outro tipo de conector?

Duas soluções se apresentam. A primeira consiste em considerar que a dissociação entonacional das cláusulas adendos cria uma sequiência de dois atos simples realizados em dois segmentos independentes. A presença do conector é o índice da função justificativa do segundo segmento em relação ao primeiro. Neste caso, os conectores porque e que são uma espécie de indicador pragmático da existência de uma conexão semântica entre os dois segmentos do enunciado, estabelecendo a coerência do discurso e a validade da justificação.

A segunda solução consiste em dizer que $\boldsymbol{Y}$ pausa porque $\boldsymbol{X}$ é uma estrutura subordinativa em que o elemento subordinante fica implícito. Isto significa dizer que na forma $Y$ pausa porque $X$ temos, na realidade, $(Y)$ pausa ( $Y$ porque $X)$. Em um enunciado como (7), o segmento porque amigo mesmo a gente num tem, né? está relacionado e é discursivamente dependente de um segmento implícito colega, ne?, o que criaria, então, uma estrutura subordinativa como: eu digo colega porque amigo mesmo a gente num tem.

A segunda solução implica dizer que em enunciados do tipo $Y$ pausa porque $X$ existe uma sequiência de um ato simples (uma asserção, uma opinião) seguido de um ato complexo: $Y$ porque justificativa. Esta solução mantém o critério de flexibilidade da subordinação. Um enunciado do tipo Porque amigo mesmo a gente num tem, eu digo colega seria teoricamente possível. Dizemos teoricamente, na medida em que contradiz a tendência verificada nos dados: cláusulas porque com função justificativa são preferencialmente pospostas. Esta solução ignoraria ainda as funções interacionais da dissociação prosódica entre os dois segmentos, uma vez que lhe atribuiria um preenchimento semântico. 
A primeira solução encontra motivação no fato de que, pela forma $Y$ pausa porque $X$, se atualiza uma configuração de informação distinta da que se realiza pela forma $Y$ porque $X$. Na forma $Y$ porque $X$, há uma dependência discursiva entre os dois segmentos do enunciado; na forma $Y$ pausia porque $X$, os dois segmentos são discursivamente independentes, independência que se reflete na sua dissociação prosódica. Dependência discursiva entendida no sentido de que, na forma $Y$ porque $X$, a codificação da informação nova (comentário) depende da colocação anterior de uma informação velha (um tema). A forma $Y$ porque $X$ realiza uma articulação temacomentário.

Outras características das cláusulas adendo vão ao encontro da primeira solução. A grande maioria dos estudos sobre subordinação aponta como uma das características deste processo a possibilidade de antepor ou pospor uma cláusula subordinada àquela com que se relaciona (Piot, 1988). A estrutura subordinativa se caracteriza, em oposição à coordenação, pela flexibilidade de ordenação dos termos. Por este critério, as cláusulas adendos não podem ser consideradas subordinativas, uma vez que não admitem qualquer mudança de posição. São, por definição, pospostas. Assim $Y$ pausa porque $X$ não seria apenas uma variante de $Y$ porque $X$, mas sim uma forma particular de realização da relação de causalidade com propriedades e funções próprias.

\section{NOTAS}

1

Este artigo foi extraído de um trabalho mais amplo sobre a ordenaçán dos enunciados causais, apresentado como tese de doutoramento. Para a análise foram examinadas três amostras de fala do Rlo de Janeiro: a Amostra Censo, uma parte da Amostra NURC-RJ e um conjunto de situaçoes de fala espontânea (Paiva, 1991).

2

Em Paiva (1991), a análise da antecipação e da posposição de cláusulas causais mostrou que as cláusulas introduzidas por porque ocorrem, geralmente, na segunda posição por codificarem informação nova.

3

Embora se trate de uma questão menos relevante para os objetivos deste texto, é preciso discinguir entre adendos não acionados e adendos acionados pelo interlocutor. 


\section{REFERÊNCIAS BIBLIOGRÂAICAS}

ANSCOMBRE, J.C. La représentation de la notion de cause dans la langue. Cahiers de grammaire, v. 8, p. 3-53, 1984. 1983.

\& DUCROT, O. L'argumentation dans la langue. Bruxelles: Mardaga,

\& ZACCARIA, G. Fonctionnalisme et pragmatique: à propos de la notion de thème. Milano: Edizioni Unicopli, 1990.

AUSTIN, J. How to do things with words. Oxford: University Press, 1975.

BROWN, G. \& YULE, G. Discourse analysis. Cambridge: Cambridge University Press, 1983.

CARONE, F. de Barros. Subordinaçẫo e coordenação. São Paulo: Atica, 1988.

CESHIRE, J. Syntactic variation, the linguistic variable and sociolinguistic theory. Linguistics, v. 25, p. 257-282, 1987.

CHIAFE, W. Giveness, contrastiveness, definiteness, subjects, topics and point of view. In: LY, Ch. N. (Ed.). Subject and topic. New York: Academic Press, 1976. p. 25-55.

- The flow of thought and the flow of language. In: GIVON, T. (Ed.). Syntax and semantics. New York: Academic Press, 1979. v. 12.

- How people use adverbial clauses. In: MEETING OF THE BERKELEY LINGUISTICS SOCIETY, 10. Proceedings... Berkeley: Berkeley Linguistics Society, 1984. p. 437-450.

-. Linking intonational unities. In: HAIMAN, J. \& THOMPSON, S. A. (Ed.). Clause combining in grammar and discourse. Philadelphia: John Benjamins Publishing Company, 1988. p. 1-28.

DUCROT, O. Polifonia y argumentación. In: Seminário Teoria de la argumentación y análisis del discurso. Conferências... Cali: Universidad del Valle, 1988.

DUCROT et al. Les mots du discours. Paris: Minuit, 1980.

- Topoi et formes topiques. Bulletin d'études de Linguistique Française. Tokio: v. 22, p. 1-14, 1988.

FORD, C. Grammar in ordinary interaction: the pragmatics of adverbial clauses in conversational English. Los Angeles: University of California, 1988. (Dissertation, PhD).

\& THOMPSON, S. A. Subordination in universal grammar. In: MEETING OF THE BERKELEY LINGUTSTICS SOCTETY, 10. Proceedings... Berkeley: Berkeley Linguistics Society, 1984, p. 510-523.

MARCUSCHI, L. A. Dicionário de termos de análise da conversação. Boletim da ANPOLL, 1989.

PAIVA, M.C. de. Ordenação das clausulas causais: forma e função. Rio de Janeiro: Faculdade de Letras, 1991. (Tese, Doutorado). 